\title{
Cognitive deficits in hospitalized and never hospitalized remitted unipolar depressive patients
}

\author{
Marek Preiss* \\ Hana Kucerova** \\ Jiri Lukavsky*** \\ Petr Sos* \\ Hana Stepankova* \\ Radka Cermakova* \\ * Prague Psychiatric Center \\ ** The Faculty Hospital Brno, Brno \\ *** Academy of Sciences, Prague \\ CZECH REPUBLIC
}

\begin{abstract}
Background and Objectives: Little is known about the differences between patients managing depression on an outpatient basis as compared with hospitalized ones. This study investigated the performance of attention, executive function and verbal memory during remission from unipolar depressive episodes and compare patients with and without history of hospitalization.

Methods: The sample of participants who had undergone one or more hospitalizations (hospitalized, $\mathrm{N}=46$ ) as well as in a sample without hospitalization (never hospitalized, $\mathrm{N}=46$ ) and controls $(\mathrm{N}=92)$ were used. The Auditory Verbal Learning Test (AVLT) and the Trail Making Test (TMT) were administrated to test this hypothesis.

Results and conclusion: The hospitalized sample had similar results in all four neuropsychological variables in comparison with the never hospitalized group, and both groups had some lower results in comparison with controls. In comparison with the controls, hospitalized sample had mean cognitive deficits of $34 \%$ (28-41\%), the never hospitalized group had a mean of $20 \%(21-35 \%)$. Contrary to previous reports we have found no meaningful differences between the two patient groups.
\end{abstract}

Received: 20 April 2009

Revised: 4 January 2010

Accepted: 9 February 2010 


\section{Introduction}

Major depression is a prevalent and disabling disorder with high rates of recurrence and chronicity ${ }^{1-2}$. Cognitive impairment is likely to be a key factor affecting the subject's ability to function occupationally ${ }^{3-6}$. The "therapeutic" aspects of mental hospitalization are generally taken for granted, and are usually considered to comprise protection, separation from a potentially pathogenic environment, and positive contact between patients and staff ${ }^{7}$.

$\mathrm{Kessing}^{8}$, who studied patients with primary affective disorders who had undergone hospitalization for depression, mania or a recurrent episode, and with no further admissions or with 2 more additional admissions, found that cognitive impairment appears to increase with the increasing number of episodes a patient has experienced. On the other hand, patients with a history of more than one hospitalization did not show any differences compared to patients experiencing their first hospitalization on most of the neuropsychological tests and clinical variables ${ }^{9}$. We might think that impaired cognitive performance in hospitalized patients relates to the fact that people with more severe symptomathology are hospitalized. The patients with a history of hospitalization had worse results than those without such a history ${ }^{10-11}$. Neuropsychological assessment is an ideal strategy for obtaining collaborative data in a psychiatric population due to the presumed absence of self-report bias ${ }^{12}$. We assumed that remitted patients who were previously hospitalized would demonstrate worse impairment of attention, memory and executive function in comparison to those remitted patients who had never been hospitalized.

\section{Material and Methods}

\section{Sample}

The study was conducted with 92 unipolar depressive outpatients (42 men and 50 women; Table 1 and 2). All the patients met the criteria for formerly having major depressive disorder according to ICD-10. All patients were in a remitted state at the time of testing. Remission was defined as a period of at least 2 months during which the subject functioned well (subjectively according to the patient and objectively according to their psychiatrist) and the MADRS on the day of study $<12$. Patients were divided into two groups: never hospitalized $(\mathrm{N}=46)$ or hospitalized $(\mathrm{N}=46)$. Controls were recruited from the general population and they were matched for age, gender and education with the test groups (Table 1).

Individuals with mental retardation (IQ < 70 according to subtest Information from WAIS-R, scale score 6 and lower), dementia, substance abuse/dependence, neurological disorders or clinical/laboratory indications of a severe organic disease, actual or prior bipolar I or II were not counted. Written consent was obtained and the study was approved by the Ethical Regional Committee for Medicine of Prague Psychiatric Center. 
Table 1

Family and occupational status in patient's group

\begin{tabular}{lcccc} 
& Hospitalized & $\%$ & Never hospitalized & $\%$ \\
\hline Family status & & & & \\
\hline Single & 6 & 13 & 11 & 24 \\
\hline Married & 31 & 67 & 23 & 50 \\
\hline Divorced & 7 & 15 & 10 & 22 \\
\hline Widow/er & 2 & 4 & 2 & 4 \\
\hline
\end{tabular}

Occupation

\begin{tabular}{lcccc}
\hline Partially disabled & 6 & 0 & 5 & 11 \\
\hline Partially disabled + employed & 6 & 13 & 1 & 2 \\
\hline Unemployed & 0 & 0 & 0 & 0 \\
\hline Maternity leave & 1 & 2 & 2 & 4 \\
\hline Household & 0 & 0 & 2 & 4 \\
\hline Student & 1 & 2 & 3 & 7 \\
\hline Fully disabled & 0 & 0 & 1 & 2 \\
\hline Old age pension & 1 & 2 & 1 & 2 \\
\hline Entrepreneur & 10 & 22 & 6 & 13 \\
\hline Employee & 27 & 59 & 23 & 50 \\
\hline Rehabilitation & 0 & 0 & 2 & 4
\end{tabular}

\section{Methods}

All subjects were given a battery of short neuropsychological tests (Table 3 ). Traditional neuropsychological criteria for cognitive impairment would identify those individuals who performed better than 1 SD below the healthy control mean as "unimpaired"13-14.

\section{Results}

As can be seen in Table 2, groups were well matched. The number of hospitalizations was rather small in the hospitalized group $(\mathrm{M}=1.9, \mathrm{SD}=1.0$; maximum 5 hos- pitalizations). On average, hospitalized patients had been hospitalized 4 years prior $(\mathrm{M}=4.2, \mathrm{SD}=3.9)$. The mean duration of illness was 17.8 years in the hospitalized group and 12.3 in never hospitalized group. The average age of the first depressive episode was 29.4 resp. 29.6 years. The mean number of depressive episodes was subjectively 2.9 vs. 2.4 and according to medical records 2.5 vs. 1.8 .

Performance of both groups is presented in Table 4. Mean z-scores of patients and controls are seen in Table 5. In comparison with the controls, all mean z-scores for the depressive groups are lower. The hospitalized sample had cognitive deficits in the AVLT Trial (28\%), in AVLT delayed recall (35\%), in the 
Table 2

Basic demographic and treatment details (means with SD in parentheses)

\begin{tabular}{|c|c|c|c|c|}
\hline & $\begin{array}{l}\text { Hospitalized } \\
\qquad(\mathrm{N}=46)\end{array}$ & $\begin{array}{l}\text { Never Hospitalized } \\
\qquad(\mathrm{N}=46)\end{array}$ & $\begin{array}{l}\text { Controls } \\
(\mathrm{N}=92)\end{array}$ & $\mathrm{p}$ \\
\hline Age & $47.3(10.4)$ & $43.5(13.0)$ & $46.2(12.0)$ & ns. \\
\hline Education* & $8.3(2.2)$ & $8.7(2.1)$ & $8.5(2.1)$ & ns. \\
\hline Gender (Male/Female) & $25 / 21$ & $17 / 29$ & $45 / 50$ & ns. \\
\hline BDI-II & $11.8(6.9)$ & $11.3(7.2)$ & $6.3(5.7)$ & $<0.001 *$ \\
\hline Information from WAIS-R & $23.3(0.3)$ & $23.8(0.3)$ & $23.5(0.2)$ & ns. \\
\hline MADRS & $4.3(3.0)$ & $4.5(3.2)$ & & ns. \\
\hline Number of hospitalizations & $1.9(1.0)$ & 0 & & ns. \\
\hline Duration of illness (years) & $17.8(9.5)$ & $12.3(17.6)$ & & ns. \\
\hline Period since last hospitalization (years) & $4.2(3.9)$ & - & & ns. \\
\hline Age when first depressive episode & $29.4(9.7)$ & $29.6(13.7)$ & & ns. \\
\hline Number of depressive episodes (subjectively) & $2.9(1.5)$ & $2.4(1.0)$ & & ns. \\
\hline $\begin{array}{l}\text { Number of depressive episodes } \\
\text { (according to medical records) }\end{array}$ & $2.5(1.1)$ & $1.8(1.0)$ & & .002 \\
\hline Psychiatric medication yes/no & $38 / 8$ & $32 / 10$ & & ns. \\
\hline \multirow[t]{2}{*}{ Type of medication } & TCA $30 \%$ & TCA $25 \%$ & & \\
\hline & $\begin{array}{l}\text { SSRI } 65 \% \\
\text { Mirtazepin 19\% } \\
\text { Other antidepresives } \\
14 \%\end{array}$ & $\begin{array}{l}\text { SSRI 75\% } \\
\text { Mirtazepin 11\% } \\
\text { Other antidepres } \\
4 \%\end{array}$ & ives & \\
\hline
\end{tabular}

\footnotetext{
* Both depressive groups differ from controls.

** Education was based on 12-point scale.
} 
Table 3

Neuropsychological screening battery

\section{Memory}

\section{Auditory Verbal Learning test}

The Auditory Verbal Learning test is a 15 -word learning task which was repeatedly ( 5 times) read to the subjects. The sums of all the correctly recalled words from first five trials as well as the sum of words recalled in the delayed recall trials (after 30 minutes) were used as memory variables. The test was proved to be valid in other studies on depression and Czech validated version of the test was used.

\section{Attention}

\section{Trail Making test (part A)}

The Trail Making test, part A, is a valid and commonly used test to assess attention and psychomotor speed. Part A consists of encircled numbers from 1 to 25 randomly spread across a sheet of paper. The objective of the test is for the subject to connect the numbers 1-25 in sequence as fast as possible. Validated Czech version of the test was used.

\section{Executive functions}

\section{Trail Making test (part B)}

Part B is more complex than part A because it requires the subject to order numbers and letters in an alternating pattern (1-A-2-B-3-C, etc.) in the shortest possible time. The Trail Making test, part B, is a valid and commonly applied test to gage cognitive flexibility. In this test a connecting line is drawn as rapidly as possible for letters and numbers in an ascending sequence. The Trail Making Test, especially Trail B, is a good predictor of brain impairment. Validated Czech version of the test was used.

\section{Table 4}

Differences between patients and controls in neuropsychological tests (Mean, SDs, p-levels; compared ANOVA, Tukey HSD post hoc test)

\begin{tabular}{llcc}
\hline & Hospitalized & Never hospitalized & Controls \\
\hline AVLT Trial 1-5 & $52.8(9.1)$ & $52.6(8.0)$ & $55.3(8.2)$ \\
\hline AVLT delayed recall & $10.2(2.7)^{*}$ & $10.5(2.9)^{*}$ & $11.2(2.8)$ \\
\hline Trail Making Test, part A & $36.9(11.2) 9^{*}$ & $34.3(12.4)$ & $32.5(9.9)$ \\
\hline Trail Making test, part B & $78.9(24.3)$ & $69.4(26.2)$ & $69.5(26.1)$ \\
\hline
\end{tabular}

* Differ from controls $(\mathrm{p}<.01)$.

Table 5

Z-scores for both patients groups

Hospitalized

Never hospitalized

\begin{tabular}{lcccc}
\hline & Mean z- score & SD & Mean z-score & SD \\
\hline AVLT 1-5 & -0.30 & 1.10 & -0.33 & 0.97 \\
\hline AVLT delayed recall & -0.59 & 0.84 & -0.52 & 0.98 \\
\hline Trail Making test, part A & -0.86 & 1.20 & -0.38 & 1.37 \\
\hline Trail Making test, part B & -0.39 & 0.82 & -0.07 & 0.98 \\
\hline
\end{tabular}


Trail Making Test, part A (41\%), and in Trail Making test, part B (30\%). The never hospitalized sample demonstrated signs of cognitive deficit in the AVLT Trial (33\%), in the AVLT delayed recall (35\%), in the Trail Making Test, part A (22\%), and in the Trail Making test, part B $(21 \%)$. In total, $34 \%$ of the hospitalized sample had cognitive deficits, and $20 \%$ of the never hospitalized sample presented the same deficiencies $(p=0.134)$.

\section{Discussion}

The hospitalized sample did not have worse results in any from 4 neuropsychological tests compared to the never hospitalized sample. The only statistically significant difference in comparison with controls was in the Trail Making test, part A, with worse performance found in the hospitalized sample and in AVLT delayed recall for both depressive samples.

Both depressive samples had significantly higher levels of subjective depressiveness according to the BDI-II in comparison with controls. These results may suggest that certain residual depressive symptomatology may affect performance in neuropsychological tests. This may be true despite the fact that no relationship between neuropsychological tests and BDI-II/MADRS was proven, besides the correlation between the MADRS and TMT-B scores $(r=-0.33, p=0.001)$.

In our data, we did not find a relationship between the number of hospitalizations and the subjectively reported depressive episodes as well as cognitive performance for separate groups, but for the whole sample of depressive patients this link was found $(r=-0.27$, $\mathrm{p}=0.008$ and $-0.33, \mathrm{p}=0.003$ ). Some negative effects of repeated depressive episodes were found in one of the four neuropsychological measures. These findings are and have been considered controversial in older studies $^{15}$. Other studies and papers have also failed to find differences between first and recurrent episodes ${ }^{16}$.

The performance of both depressive groups is below the mean scores of the controls, but does not exceed $66 \%$ in the hospitalized sample and $80 \%$ in the never hospitalized sample, -1 SD below the mean of controls. Level of cognitive deficits varied in hospitalized sample from $28-41 \%$ and in never hospitalized from 21-35\%. According to Gauss curve, in this range should be about $15.86 \%$ patients.

\section{Acknowledgements}

Funding for this study was provided by MŠMT 1M0517.

\section{References}

1. Ayuso-Mateos JL, Vázquez-Barquero JL, Dowrick C, Lehtinen V, Dalgard OS, Casey P, et al. Depressive disorders in Europe: Prevalence figures from the ODIN group. Brit J Psychiat 2001; 179: 308-316.

2. Marvel CHL, Paradiso S. Cognitive and neurological impairment in mood disorders. Psychiatric Clinics of North America 2004; 27: 19-36.

3. Hirchsfeld RMA. Long-term nature of depression. Depress Anxiety 1998; 7: 1-4.

4. Ormel J, Oldehinkel AJ, Nolen WA, Volleberg W. Psychosocial disability before, during, and after a major depressive episode. Arch Gen Psychiat 2004; 61: 387-392.

5. Basso MR, Bornstein RA. Neuropsychological deficits in psychotic versus nonpsychotic unipolar depression. Neuropsychology 1999;13:69-75. 
6. Thase ME. Defining remission in patients treated with antidepressants. J Clin Psychiat 1999; 60: 3-6.

7. Zaslove MO, Ungerleider T, Fuller M. How psychiatric hospitalization helps: Patient views v.s. staff views. J Nerv Ment Dis 1966; 142: 568-576.

8. Kessing LV. Cognitive impairment in the euthymic phase of affective disorder. Psychol Med 1998; 28: 1027-1038.

9. Harvey PO, Bastard G, Pochon JB, Levy R, Allinaire JF, Dubois B, et al. Executive functions and updating of the contents of working memory in unipolar depression. J Psychiat Res 2004; 38: 567-576.

10. Elliott R, Sahakian BJ, McKay AP, Herrod JJ, Robbins TW, Paykel ES. Neuropsychological Impairments in Unipolar Depression: The Influence of Perceived Failure on Subsequent Performance. Psychol Med 1996; 26: 975-989.

11. Purcell R, Maruff P, Kurios M, Pantelis C. Neuropsychological function in young patients with unipolar major depression. Psychol Med 1997; 27: 1277-1285.

12. Fleming SF, Blasey Ch, Schatzberg AF. Neuropsychological correlates of psychotic features in major depressive disorders: A review and meta-analysis. Psychiat Res 2004; 38: 27-35.
13. Bryson GJ. Differential rate of neuropsychological dysfunction in psychiatric disorders: Comparison between the Halstead-Reitan and Luria-Nebraska batteries. Percept Mot Skills 1993; 76: 305-306.

14. Ballard C, Stephens S, Kenny RA, Tovee KM, O'Brien J. Profile of Neuropsychological Deficits in Older Stroke Survivors without Dementia. Dement Geriatr Cogn Disord 2003; 16: 52-56.

15. Austin MP, Mitchell P, Goodwin GM. Cognitive deficits in depression. Possible implications for functional neuropathology. Brit J Psychiat 2001; 178: 200-206.

16. Oldenhinkel AJ, Berg MD, Bouhuys AL, Ormel J. Do depressive episodes leads to accumulation of vulnerability in the elderly? Depress Anxiety 2003;18: 67-75.

Address for correspondence:

Marek Preiss

Prague Psychiatric Center

Ustavni 91, Praha 8-Bohnice, 181 03, Czech Republic Tel.: 420266003338

Fax: 420266003366

E-mail: preiss@pcp.lf3.cuni.cz 